\title{
Numerical analysis on the heat transfer of three types of nozzles for the hypersonic long-run wind tunnel
}

\author{
XING YunFei, ZHONG FengQuan", LI DongXia \& ZHANG XinYu \\ National Key Laboratory of High Temperature Gas Dynamics, Institute of Mechanics, Chinese Academy of Sciences, Beijing 100190, China
}

Received October 13, 2014; accepted December 29, 2014; published online January 29, 2015

\begin{abstract}
The hypersonic long-run scramjet test tunnel is one of the key ground facilities for the studies of ramjet/scramjet and hypersonic thermal management. Due to the significantly large heat loading, the nozzle of the tunnel facility demands effective cooling protection. In this work, the two-dimensional, three-dimensional and axisymmetric Mach 6.5 nozzles at an inlet total temperature of $1840 \mathrm{~K}$ and a total pressure of $6.4 \mathrm{MPa}$ were studied with main focuses on the properties of aerodynamic heating of nozzles. The present work aims to provide insights into the design of an effective cooling system for the nozzle and other components of the hypersonic long-run wind tunnel.
\end{abstract}

hypersonic scramjet test tunnel, nozzle, aerodynamic heating, convective heat transfer

Citation: Xing Y F, Zhong F Q, Li D X, et al. Numerical analysis on the heat transfer of three types of nozzles for the hypersonic long-run wind tunnel. Sci China Tech Sci, 2015, 58: 470-475, doi: 10.1007/s11431-014-5764-1

\section{Introduction}

The hypersonic tunnel facilities have been widely used for researches of aerodynamic and propulsive performances of hypersonic vehicles as well as thermal management [1-3]. There are many literatures [4-8] focusing on the heat transfer performance of the facilities. Nozzle is the key element of tunnel system to generate hypersonic flow with desirable qualities. For hypersonic long-run tunnel facility, thermal protection of nozzle is critical since total temperature and total pressure upstream of the nozzle is relatively large and heat flux at the nozzle throat is very high [9-14]. Therefore, study of distribution of wall heat flux and heat transfer coefficient is very important for cooling design and optimization of nozzle.

Quentmeyer and Roncace [9] conducted an experimental investigation to determine hot-gas-side heat transfer characteristics for a rocket nozzle apparatus. Heat flux and tem-

*Corresponding author (email: fzhong@imech.ac.cn) perature profiles along the flow direction were obtained and a wall heat flux peak was observed at the nozzle throat. Kubota et al. [10] studied convective heat transfer of plug nozzle and developed a thermal analysis tool for design and optimization of nozzle cooling. Tomioka et al. [11-14] described a blow-down type, semi-free-jet, high enthalpy wind tunnel facility of JAXA-KSPC (Ramjet Engine Test Facility, i.e. RJTF). The RJTF facility can simulate flight conditions of Mach 4, 6, and 8 for ramjet and scramjet applications. As the papers claimed, nozzle is one of the key elements of the facility and nozzle cooling is one of the most critical designs.

Although there are some basic researches on heat transfer properties of nozzle, detailed study on heat transfer of hypersonic nozzle is quiet limited. It is known that the same outlet flow condition can be obtained with varied nozzle configurations such as two-dimensional, three-dimensional and axisymmetric nozzle as illustrated in Figures 1(a)-(c). For two-dimensional nozzle, the area of cross section is changed only by the nozzle height and the width of nozzle 
is kept the same. Therefore, the height of the nozzle throat is usually very small (the height of two-dimensional nozzle throat may be a few millimeters). For three-dimensional nozzle, all the nozzle faces are changed equally to obtain the desired cross section and the size of the throat is significantly larger than that of the two-dimensional nozzle with the same inlet flow conditions and the same outlet size as shown in Figures 1(a) and (b). Axisymmetric nozzle is similar to the three-dimensional nozzle with a significantly large throat compared to the two-dimensional nozzle.

Table 1 summarizes major features of the three types of nozzles when the inlet flow condition $\left(P_{0}=6.4 \mathrm{MPa}\right.$, $\left.T_{0}=1840 \mathrm{~K}\right)$ and the outlet area $\left(A_{e}=0.1089 \mathrm{~m}^{2}\right)$ and the flow Mach number $(M a=6.5)$ are kept the same. Details of the nozzle design, especially the shape of divergent section to diminish the effect of shock reflection on the main flow can be found in our previous work [10]. It is expected that due to varied nozzle configurations, flow and heat transfer properties of the three nozzles should be pretty different.

In the present paper, numerical simulations of flow and convective heat transfer of nozzles with varied configurations are conducted. The heat flux peaks at the nozzle throat are obtained and compared for the two-dimensional and three-dimensional nozzles.

\section{Numerical method and boundary conditions}

Navier-Stokes equations of compressible flow are solved with finite volume method of which, the convective term is

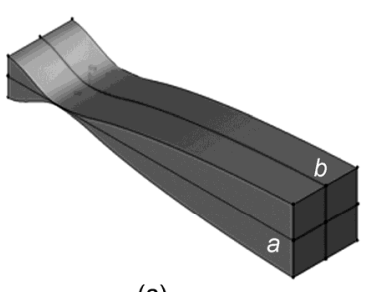

(a)

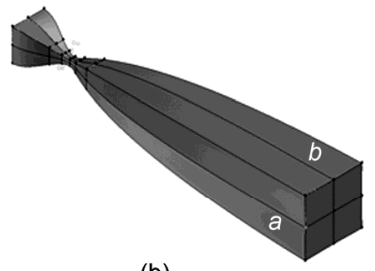

(b)

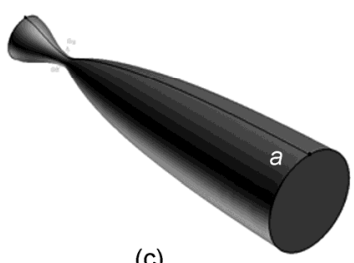

(c)

Figure 1 Sketch-up of three nozzles. (a) Two-dimensional nozzle; (b) three-dimensional nozzle; (c) axisymmetric nozzle.

Table 1 Comparison of the main properties of the three types of nozzles

\begin{tabular}{cccc}
\hline Item & $\begin{array}{c}\text { Two-dimensional } \\
\text { nozzle }\end{array}$ & $\begin{array}{c}\text { Three-dimensional } \\
\text { nozzle }\end{array}$ & $\begin{array}{c}\text { Axisymmetric } \\
\text { nozzle }\end{array}$ \\
\hline \multirow{2}{*}{ Throat size } & $\begin{array}{c}\text { Small }(2.82 \mathrm{~mm} \\
\times 330 \mathrm{~mm})\end{array}$ & Large & Medium \\
Manufacture & Easy & Difficult & $(d=30.5 \mathrm{~mm})$ \\
\hline
\end{tabular}

calculated the AUSM flux-splitting with the 2nd-order upwind scheme and the viscous terms are approximated by the 2nd-order central differencing scheme. The implicit GaussSeidel iteration algorithm is used to handle the time advance of Navier-Stokes equations. Since the nozzle flow is fully turbulent, the SST $k$ - $\omega$ model is applied to simulate turbulence.

As shown in Figure 2, a quarter of the three nozzles are used as the computational domain due to symmetry of the nozzle flow. The inlet flow conditions are set as follows: The total pressure is $6.4 \mathrm{MPa}$, the total temperature is 1840 $\mathrm{K}$ and the mass flow rate is $5.3 \mathrm{~kg} / \mathrm{m}^{3}$. The no slip and no penetration boundary with a constant temperature of $600 \mathrm{~K}$ are used for the nozzle wall. Symmetrical condition is applied at the centerlines of the nozzle and the non-reflection boundary is for the nozzle outlet.

\subsection{Grid independence}

A grid-independence study has been carried out for the validation of numerical method. Two meshes for the twodimensional nozzle as described in Figure 1(a) are given in Table 2, where $N_{x}$ is the grid number in the main flow direction, and $N_{y}$ is the grid number in the vertical direction. $\Delta r_{\max } / \Delta r_{\min }$ is the ratio of the maximum to the minimum cell sizes and $y_{\min }^{+}$is the first grid spacing from the wall normalized by the wall unit. For accurate simulation of turbulent heat transfer, $y_{\min }^{+}$should always be kept to be small to resolve small scales of turbulent boundary layer. It is worthy noticing that the stretching of grid near the wall needs sophisticated adjustments since the nozzle size decreases remarkably when approaching the throat.

Figure 3 presents distributions of the wall heat flux (the nozzle wall temperature is fixed as $600 \mathrm{~K}$ ) along the flow direction obtained with the three meshes. It is clearly seen that wall heat flux calculated with the three meshes are close to each other except in the region near the nozzle throat. As shown in the zoom-in of the figure in the vicinity of throat, heat flux results of mesh 1 and 2 agree quite well with each other. However, result of mesh 3 shows os-

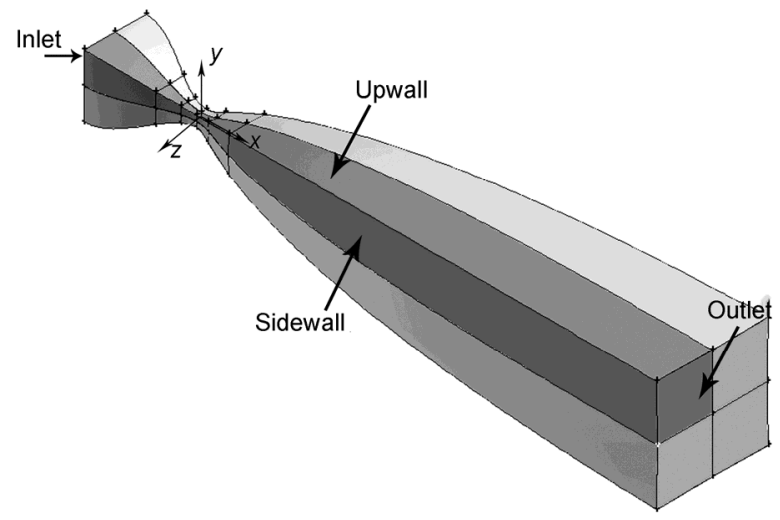

Figure 2 Computational domain for a three-dimensional nozzle. 
Table 2 Mesh parameters

\begin{tabular}{ccccc}
\hline Mesh & $N_{x}$ & $N_{y}$ & $\frac{\Delta r_{\max }}{\Delta r_{\min }}$ & $y_{\text {min }}^{+}$ \\
\hline 1 & 520 & 140 & 1509 & 1.6 \\
2 & 520 & 120 & 811 & 4.5 \\
3 & 520 & 120 & 405 & 10.2 \\
\hline
\end{tabular}

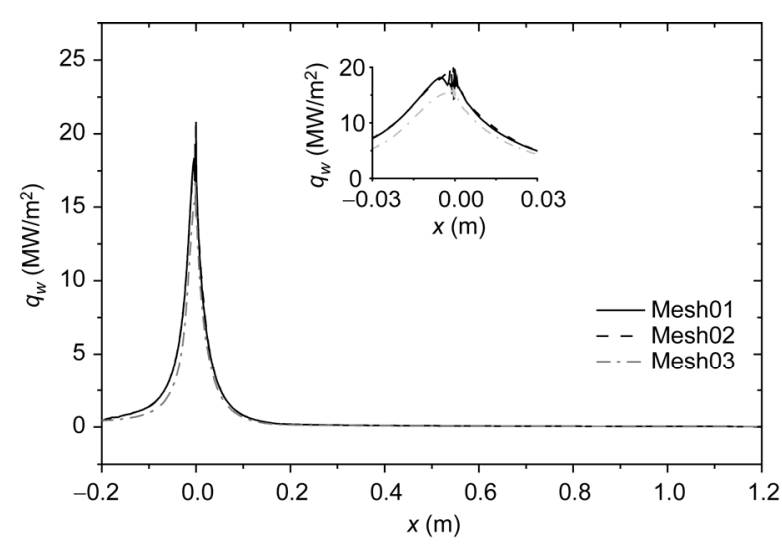

Figure 3 Distributions of wall heat flux along the flow direction with three meshes.

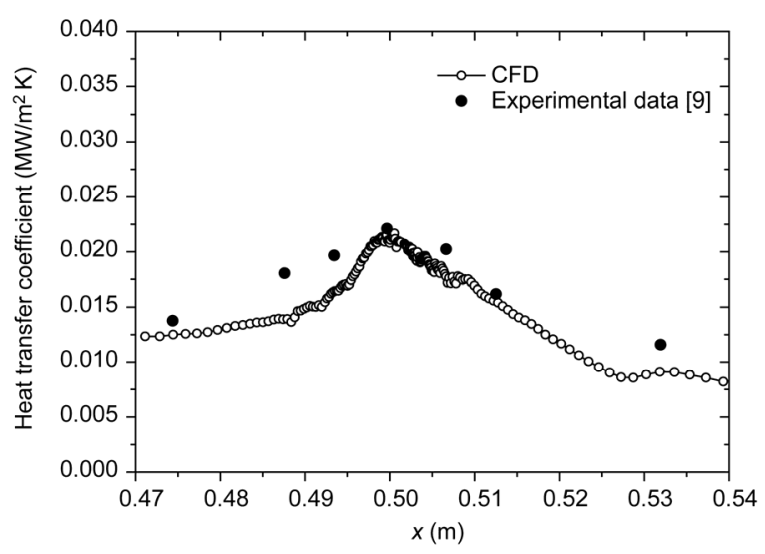

Figure 4 Comparison of distribution of heat transfer coefficient by CFD and experiment.

cillations due to relatively coarse meshes near the nozzle throat. Therefore, for the present numerical study, mesh similar to the size of mesh 2 is applied.

\subsection{Comparison with experimental heat transfer data}

The accuracy of present numerical method is further examined by comparing the calculated heat transfer coefficient with the experimental data of Quentmeyer and Roncace [9]. The test was conducted using liquid oxygen and gaseous hydrogen as the propellants over a mixture ratio of 6 at a nominal chamber pressure of $4.14 \mathrm{MPa}$. Figure 4 plots the comparison of heat transfer coefficient as defined as $h=\frac{q_{w}}{T_{r}-T_{w}}$, where $q_{w}$ is the heat flux on the wall, $T_{r}$ is the recovery temperature and $T_{w}$ is the wall temperature. It is found that heat transfer coefficient obtained by the present calculation agrees well with the experimental data in overall with a maximum discrepancy of $27.8 \%$.

\section{Results and discussion}

\subsection{Results of Mach number distribution}

Figures 5(a)-(c) shows the Mach number contours for the three nozzles. The outlet Mach numbers reach 6.5 for varied nozzles. There exists a boundary layer downstream of the nozzle throat, which decreases the effective area for the desired hypersonic flow. It is found the velocity boundary layers of the two-dimensional nozzle and three-dimensional nozzle are slightly thicker compared to that of the axisymmetric nozzle. The Mach number contours in the outlet cross section are plotted in Figures 6(a)-(b) for the two-dimensional nozzle and three-dimensional nozzle. Note that outlet is one-dimensional for the axisymmetric nozzle. One can see that the three-dimensional nozzle can get a more uniform and more effective Mach number distribution on the outlet cross section. The effective flow area can be calculated based on the national standard for wind tunnel. Detailed information about the effective flow area ratios, which is the ratio of the effective flow area to the outlet flow area, are listed in Table 3. One can see that the axisymmetric nozzle gets more effective flow area because of the relatively thinner boundary layer at the outlet.

\subsection{Total temperature distributions}

Figure 7 shows the total temperature distributions with three
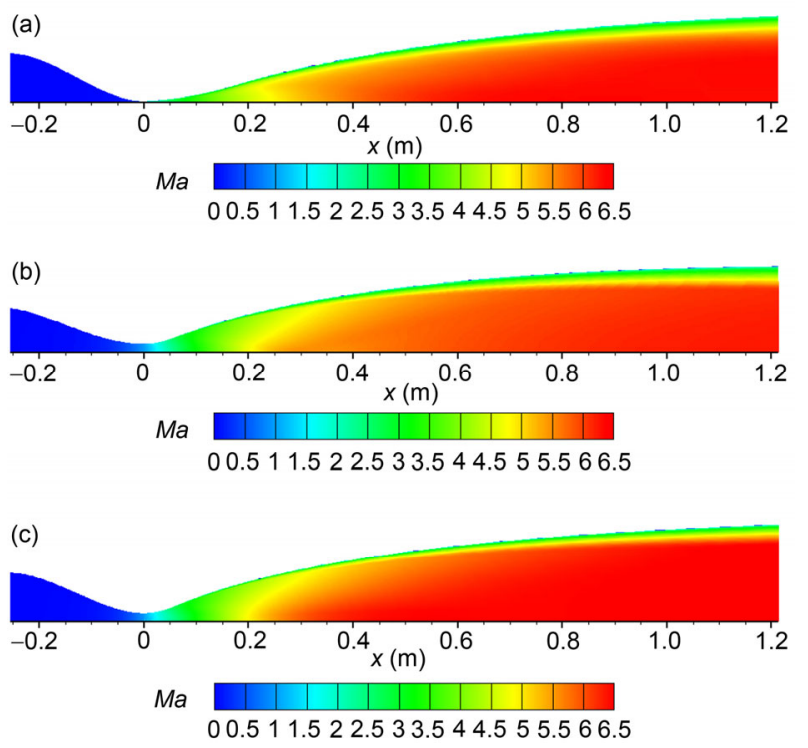

Figure 5 (Color online) Distributions of Mach number of the three nozzles. (a) Two-dimensional nozzle; (b) three-dimensional nozzle; (c) axisymmetric nozzle. 


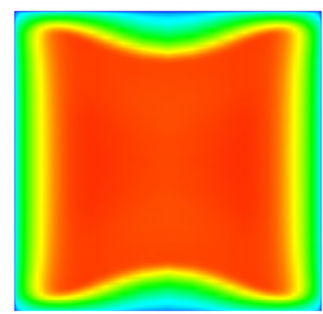

(a)

Ma

$\begin{array}{llllllllllllll}0 & 0.5 & 1 & 1.5 & 2 & 2.5 & 3 & 3.5 & 4 & 4.5 & 5 & 5.5 & 6 & 6.5\end{array}$

Figure 6 (Color online) Distributions of Mach number in the outlet cross section. (a) Two-dimensional nozzle; (b) three-dimensional nozzle.

Table 3 Effective flow area

\begin{tabular}{cccc}
\hline$\frac{A_{f}}{A_{e}}$ & $\begin{array}{c}\text { Two-dimensional } \\
\text { nozzle }\end{array}$ & $\begin{array}{c}\text { Three-dimensional } \\
\text { nozzle }\end{array}$ & $\begin{array}{c}\text { Axisymmetric } \\
\text { nozzle }\end{array}$ \\
\hline $56.7 \%$ & $67.8 \%$ & $78.2 \%$ \\
\hline
\end{tabular}

(a)

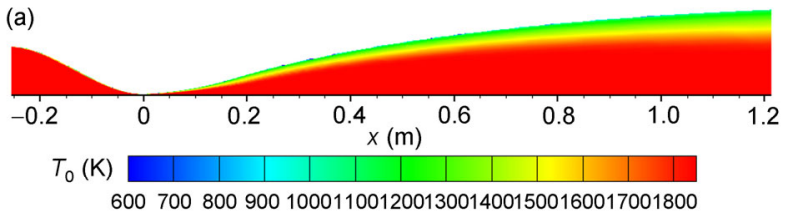

(b)
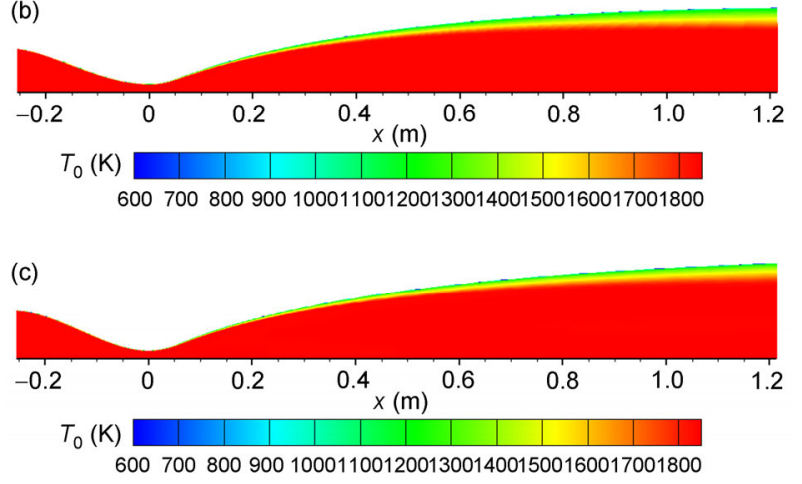

Figure 7 (Color online) Distributions of total temperature of the three nozzles. (a) Two-dimensional nozzle; (b) three-dimensional nozzle; (c) axisymmetric nozzle.

different nozzles. Similar to results of velocity boundary layer, the temperature boundary layer of the two-dimensional nozzle is the thickest. The total temperature contours in the outlet cross section are plotted in Figures 8(a)-(b) for the two-dimensional nozzle and the three-dimensional nozzle. One can see that the three-dimensional nozzle and the axisymmetric nozzle could provide a better temperature profile at the nozzle outlet.

\subsection{The heat flux distribution on the wall}

Figure 9(a) shows the distribution of wall heat flux along lines $a$ and $b$ (as indicated in Figure 1) for the

two-dimensional nozzle. It is found that the change of wall heat flux on both the sidewall and the main curved wall has a similar tendency. However, heat flux on the main wall is much higher than that on the side wall at the nozzle throat. For three-dimensional nozzle as shown in Figure 9(b), distributions of wall heat flux along line a and line $b$ are observed to be nearly the same since the four walls of the three-dimensional nozzle change equally to obtain a desirable shape of the nozzle.

Because outlet areas of different nozzles are the same, the throat size of three-dimensional nozzle is the largest

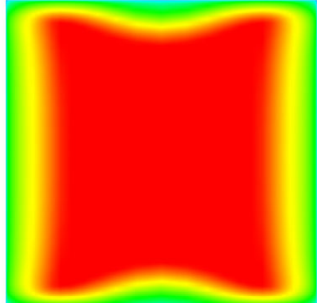

(a)

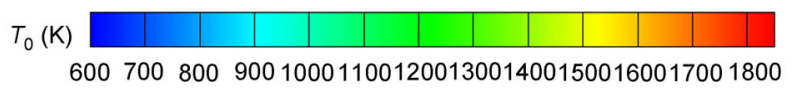

Figure 8 (Color online) Distributions of total temperature in the outlet cross section. (a) Two-dimensional nozzle; (b) three-dimensional nozzle.
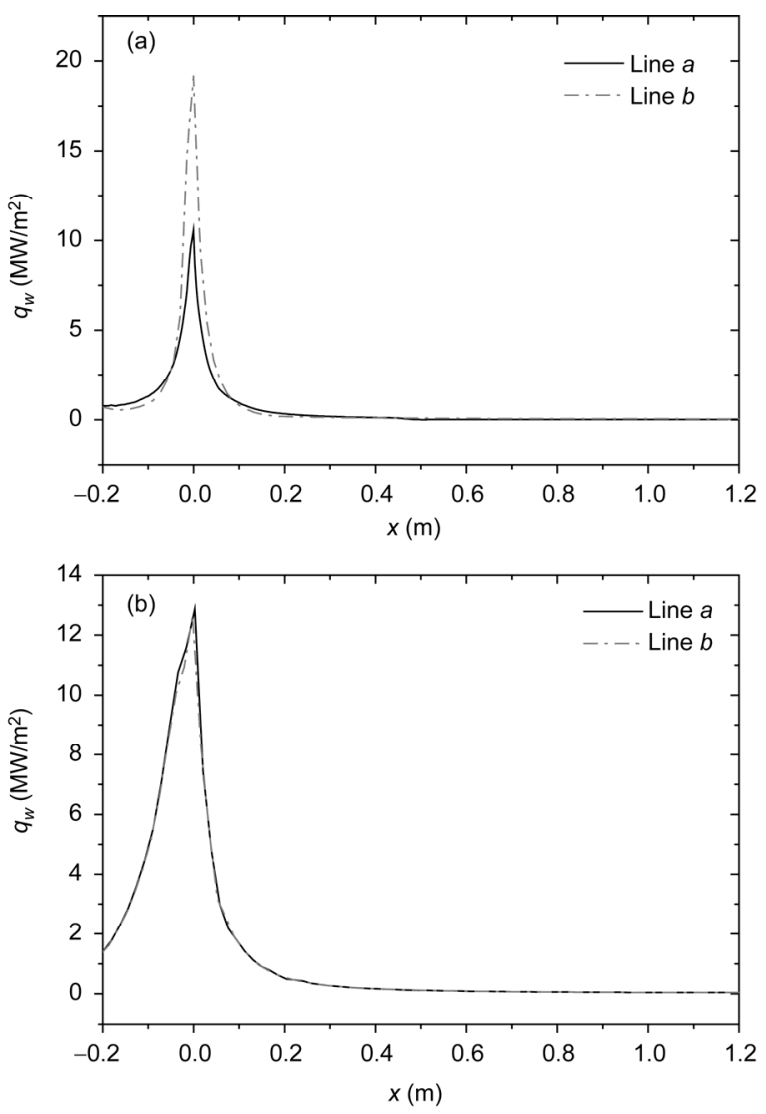

Figure 9 The heat flux on the wall with two-dimensional and threedimensional nozzles. (a) Two-dimensional nozzle; (b) three-dimensional nozzle. 
one. For two-dimensional nozzle, the height of nozzle is very small because the area of the cross section is changed only by the nozzle height. Figure 10 compares the heat flux distributions on the line $b$ as indicated in Figure 1 for different nozzles. In the convergent part of the nozzle, the wall heat flux of the two-dimensional nozzle gives the lowest value. However, as approaching the nozzle throat, the wall heat flux of two-dimensional nozzle presents the maximum value of approximately $18 \mathrm{~W} / \mathrm{m}^{2}, 45 \%$ higher than the value of the other two nozzles. It indicates that the heat loading at the throat of two-dimensional nozzle is most serious; therefore the cooling design is most critical. Downstream of the throat, the wall heat flux for the three nozzles all decreases rapidly and reaches as low as $0.05 \mathrm{~W} / \mathrm{m}^{2}$ at a location with a distance of only $400 \mathrm{~mm}$ apart from the throat. Therefore, heat flux on a nozzle wall is remarkably non-uniform and the region in the vicinity of the throat should be protected with a highly efficient cooling system with careful design. Figure 11 compares the heat transfer coefficients on line $b$ for different nozzles. Similar results are obtained compared to heat flux.

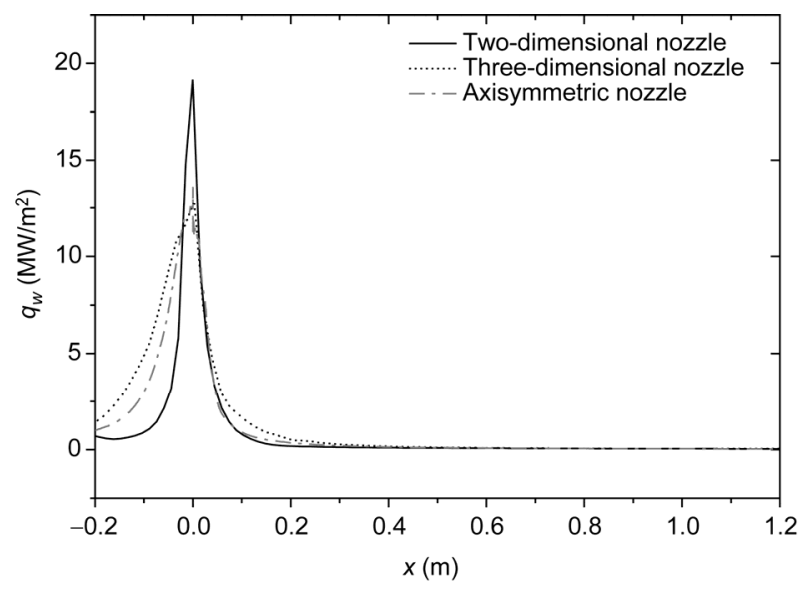

Figure 10 The heat flux distributions along the nozzle line $b$ with different nozzles.

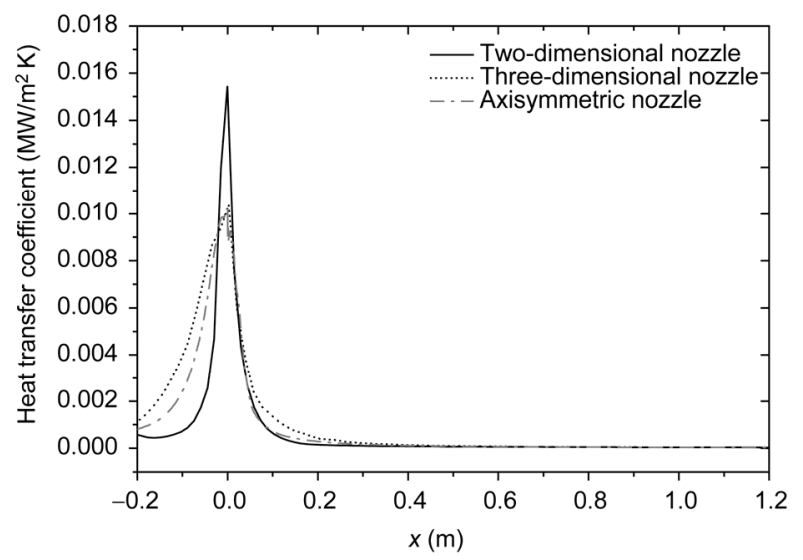

Figure 11 The heat transfer coefficients along the nozzle line $b$ with different nozzles.

\subsection{The heat flux distribution at the throat}

Here, one also should notice the heat flux distribution in the spanwise direction ( $z$ direction as shown in Figure 2$)$ at the throat for the two-dimensional and the three dimensional nozzles.

It is quite necessary to study the distribution of heat flux along the circumference of the nozzle wall at the throat point. Figure 12 give the heat flux along the $z$ and the $y$ directions for the two-dimensional nozzle. It is found that wall heat is quite uniform in the center region of the nozzle wall and only decrease in the corner region. For the threedimensional nozzle as shown in Figure 13, the heat flux decreases towards the corner for both the upper and the side walls. For both nozzles, the centerlines get the highest wall heat flux and there is no local heat flux peak near the corners.

\section{Conclusion}

The aerodynamic heating of nozzle for hypersonic long-run scramjet test tunnel is investigated in the present paper. The heat flux distributions are discussed for the two-dimensional, three-dimensional and axisymmetric nozzles. Two-dimensional nozzle gets the highest heat flux because of the minor
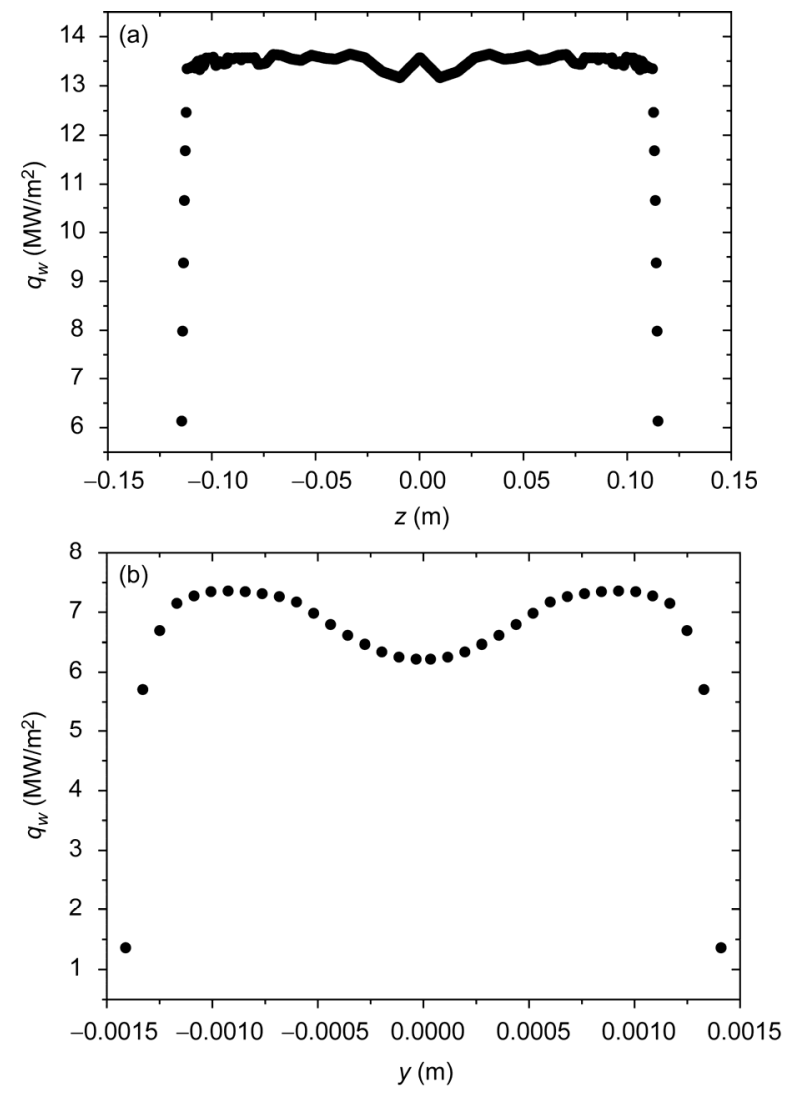

Figure 12 The heat flux distribution on the upper and side walls for the two-dimensional nozzle. (a) On the upper wall $(x=0)$; (b) on the side wall $(x=0)$. 


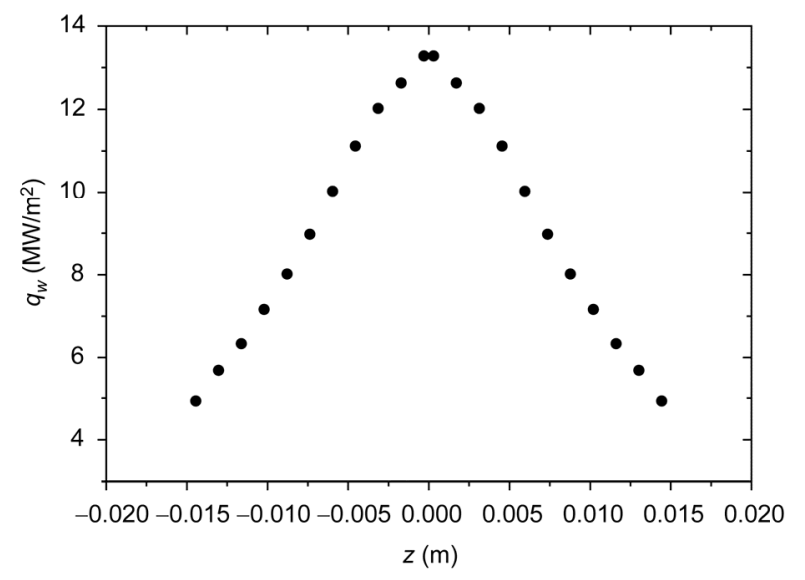

Figure 13 The heat flux distribution on the throat for the three-dimensional nozzle.

nozzle height at the throat. The heat transfer performance at the throat for two-dimensional, three-dimensional nozzle is also mentioned for the non-axial nozzle shape. There is no local heat peak caused by the corner. The three-dimensional and axisynmetric nozzles could obtain a lower heat flux at the throat. The heat flux distributions at the throat have also been discussed in the present paper.

This work was supported by the National Natural Science Foundation of China (Grant Nos. 11202218 and 11172309).

1 Woodling M A. Restoration of the hypersonic tunnel facility at NASA Glenn research center, plum brook station. AIAA Paper 2000-0163
2 Woike M R, Willis B P. Mach 6 integrated systems testing for the hypersonic tunnel facility. AIAA Paper 2000-2446

3 Thomas S, Lee J, Stephens J, et al. The mothball, sustainment, and proposed reactivation of the hypersonic tunnel facility (HTF) at NASA Glenn Research Center Plum Brook Station. AIAA Paper 2010-4533

4 Huang S, Wang W, Wang Z, et al. Experimental study of hypervapotron under conditions of high heat flux. Sci China Tech Sci, 2013, 56: 222-227

5 Chen L, Tang X, Jiang X, et al. Theoretical study on boiling heat transfer in the Xi' an pulsed reactor. Sci China Tech Sci, 2013, 56: 137-142

6 Deng Y, Quan Z, Zhao Y, et al. Experimental investigations on the heat transfer characteristics of micro heat pipe array applied to flat plate solar collector. Sci China Tech Sci, 2013, 56: 1177-1185

7 Zhu X, Zhang J, Tan X. Numerical simulation on heat transfer inside rotating porous disk subjected to local heat flux. Sci China Tech Sci, 2013, 56: 1657-1666

8 Xia G, Zhai Y, Cui Z. Characteristics of entropy generation and heat transfer in a microchannel with fan-shaped reentrant cavities and internal ribs. Sci China Tech Sci, 2013, 56: 1629-1635

9 Quentmeyer R J, Roncace E A. Hot-gas-side heat transfer characteristics of subscale, plug-nozzle rocket calorimeter chamber. NASA technical paper 3380

10 Kubota I, Asakawa H, Nanri H, et al. Improvement of design evaluation on ablative cooled combustion chamber for a LNG ricket engine. AJCPP2014-069

11 Hiraiwa T, Sato S, Tomioka S, et al. Testing of a scrmajet engine model in mach 6 vitiated air flow. AIAA Paper 1997-0292

12 Tomioka S, Kanda T, Tani K, et al. Testing of a scramjet engine with a strut in M8 flight conditions. AIAA Paper 1998-3134

13 Tomioka S, Ueda S, Tani K, et al. Scramjet engine tests at ramjet engine test facility in JAXA-KSPC. AIAA Paper 2007-1040

14 Mitani T, Tomioka S, Kanda T, et al. Scramjet performance achieved in engine tests from mach 6 to mach 8 flight condition. AIAA Paper 2003-7009

15 Zhong F, Xing Y, Song H, et al. Heat analysis and cooling optimization of nozzles for hypersonic long-run tunnel facility. In: the 4th Hypersonic Science and Technology Conference. Sanya, 2011 